\title{
The intriguing modeling of cis-trans selectivity in ruthenium-catalyzed olefin metathesis
}

\author{
Naeimeh Bahri-Laleh ${ }^{1,2}$, Raffaele Credendino ${ }^{1}$ and Luigi Cavallo*1
}

\section{Letter}

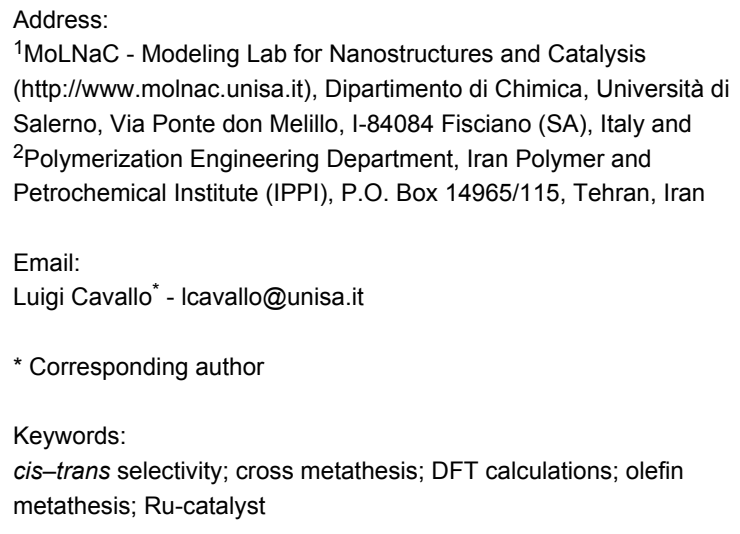

\begin{abstract}
In this study we have investigated computationally the origin of the cis-trans selectivity in the Ru-catalyzed cross metathesis (CM) of a prototype monosubstituted olefin, i.e., propene. Our calculations suggest that the origin of the preferential formation of transolefins is in the product release step, which prevents the initially formed cis-olefin from escaping the metal, and returns it to the reaction pool until the trans-olefin is formed.
\end{abstract}

\section{Introduction}

Olefin metathesis is among the most versatile tools when $\mathrm{C}=\mathrm{C}$ double bonds must be manipulated. For this reaction $\mathrm{Ru}$-based catalysts of various generations are particularly attractive due to their high tolerance for other functional groups [1-4]. Among the most useful possibilities is cross metathesis (CM), see Scheme 1, since it opens the door to the formation of functionalized and/or higher olefins from simpler unsaturated building blocks. Such a wide potential explains why CM applications span from the production of raw materials $[5,6]$ to advanced and challenging organic synthesis [7-10]. On the other hand, the general scope of CM has made a challenging task the comprehension of the working mechanism and the development of rules to control this powerful synthetic tool [11-18]. Among the problems connected with the CM of reactive monosubstituted olefins are the minimization of homodimers and a control over the cis-trans selectivity, see Scheme 1. While minimization of homodimers can be achieved with proper handling of the reaction protocol [15], controlling the cis-trans selectivity is much more complicated, and is usually biased towards the formation of the trans-isomer. 


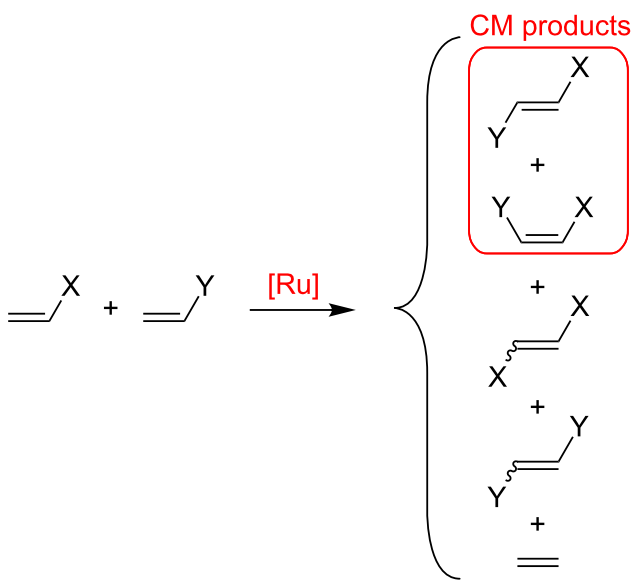

Scheme 1: Possible products resulting from the $\mathrm{CM}$ of terminal olefins.

For this reason, we decided to investigate computationally the cis-trans selectivity in the CM of the simplest terminal olefin, i.e., propene, to yield either cis- and trans-2-butene with the well characterized $2^{\text {nd }}$ generation Ru-catalyst based on the SIMes $N$-heterocyclic carbene ligand, see Scheme 2. Although it is well known that the steric hindrance of the olefin substituent has a remarkable role on both reactivity and prod- ucts distribution, propene can still be considered as a prototype of terminal olefins, and can provide insights into the energetics of the basic CM reaction. Steric or electronic effects that would arise from more complex olefins would add to the prototype energy profile investigated here. Finally, for the sake of brevity, we will focus only on the productive CM of propene with the $\mathrm{Ru}$-propylidene bond, while degenerate propene metathesis with the Ru-propylidene moiety, or propene reactivity with the $\mathrm{Ru}$-methylidene moiety, which would be the other Ru-alkylidene bonds present in the reaction mixture after complete activation of the starting precatalyst, are not considered.

\section{Results and Discussion}

The free energy profile in $\mathrm{CH}_{2} \mathrm{Cl}_{2}$ for the formation of both cisand trans-2-butene from the starting $14 \mathrm{e} \mathrm{Ru}$-propylidene species is shown in Figure 1. Coordination of propene to the $\mathrm{Ru}$ center of 14e1, leading to the coordination intermediate Co1, is favored by $3.4 \mathrm{kcal} \cdot \mathrm{mol}^{-1}$. In this intermediate the $\mathrm{C}=\mathrm{C}$ double bond of the coordinated propene molecule is roughly perpendicular to the Ru-propylidene bond. From intermediate Co1, two transition states corresponding to productive metathesis, TS1cis and TS1-trans, can be reached via rather low energy barriers (3.1 and $2.5 \mathrm{kcal} \cdot \mathrm{mol}^{-1}$ for TS1-cis and TS1-trans, respectively). The two transition states differ in the relative orientation of the Me groups of the propene group and of the propylidene

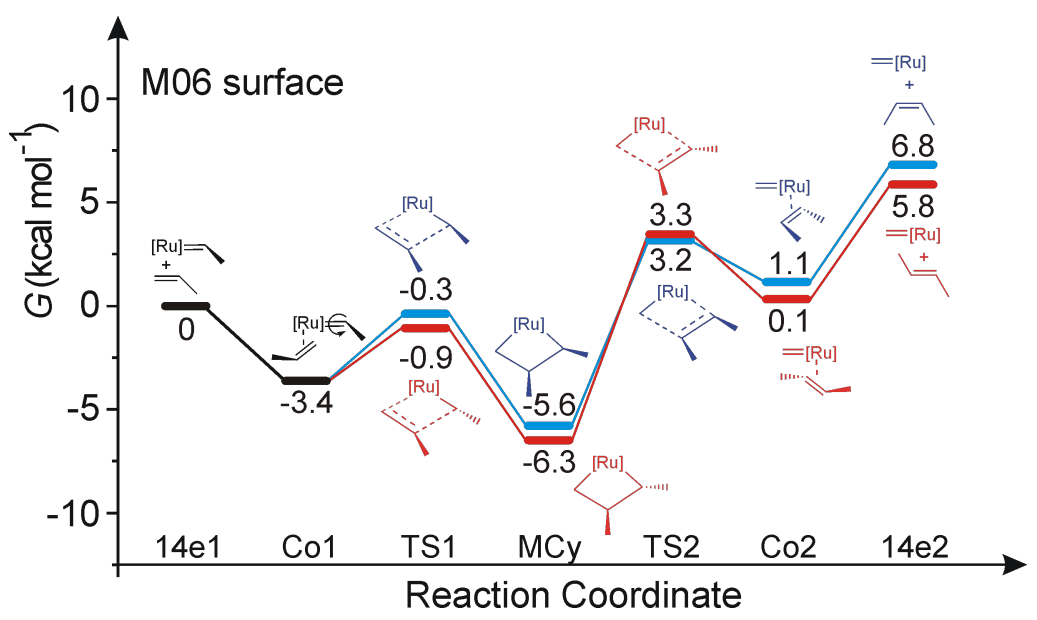

Figure 1: Reaction profile for the formation of cis- and trans-2-butene. 
moiety, syn in TS1-cis, and anti in TS1-trans, with TS1-trans favored by $0.6 \mathrm{kcal} / \mathrm{mol}$ The experimentally proved free and fast rotation around the $\mathrm{Ru}$-alkylidene bond allows both TS1cis and TS1-trans to be reached from Co1 [19,20]. The two transition states collapse into the corresponding MCy-cis and MCy-trans metallacycles, at 5.6 and $6.3 \mathrm{kcal} \cdot \mathrm{mol}^{-1}$ below the starting 14e1 intermediate, respectively. The two metallacycles are the most stable structures along the reaction pathway. Release of cis- and trans-butene requires the breaking of the MCy-cis and MCy-trans metallacycles through the transition states TS2-cis and TS2-trans, respectively, with formation of the two coordination intermediates Co2-cis and Co2-trans, from which cis- and trans-butene are released. In this case, breaking the metallacycles is energetically quite expensive, around 9-10 $\mathrm{kcal} \cdot \mathrm{mol}^{-1}$, and transition states TS2-cis and TS2trans, in agreement with other computational studies, are higher in energy than the transition states for metallacycle formation TS1-cis and TS1-trans [21]. The Co2-cis and Co2-trans coordination intermediates are slightly more stable than the corresponding TS2-cis and TS2-trans transition states, which means that the energy barrier for the backward reaction that would return the Co2-cis and Co2-trans coordination intermediates back into the corresponding metallacycle is rather low (2.1 and $3.2 \mathrm{kcal} \cdot \mathrm{mol}^{-1}$ for Co2-cis and Co2-trans, respectively).

This scenario indicates a rather surprising and unexpected result. First, cis versus trans selectivity is not determined at metallacycle formation, since both the cis and trans TS1 transition states are roughly 3-4 $\mathrm{kcal} \cdot \mathrm{mol}^{-1}$ lower in energy that the TS2 transition states. Second, neither is selectivity determined at metallacycle breaking. In fact, the TS2-cis and TS2-trans transition states, within the accuracy of this type of calculation, are of the same energy. On the other hand, and in line with expectations, the MCy-trans metallacycle is more stable than the MCy-cis metallacycle by roughly $1 \mathrm{kcal} \cdot \mathrm{mol}^{-1}$, and the Co2-trans coordination intermediate is similarly more stable than the Co2-cis coordination intermediate. Finally, our computational approach also reproduces well the experimental higher stability, by $1.0 \mathrm{kcal} \cdot \mathrm{mol}^{-1}$, of trans-2-butene relative to cis-2butene in the gas-phase [22].

To test whether the relative stability of the four transition states could depend on the chosen HMGGA M06 functional [23], we localized the transition states for metallacycle formation and breaking with the popular GGA BP86 [24-26] and HGGA B3LYP [27-29] functionals, as well as with the more recent MGGA M06L functional [30]. All these tests are summarized in Table 1. First, in all the cases TS1-cis is somewhat higher in energy than TS1-trans but, more importantly, both the TS1 metallacycle forming transition states are $3-5 \mathrm{kcal} \cdot \mathrm{mol}^{-1}$ lower in energy than the TS2 metallacycle breaking transition states. Considering that all the functionals we considered indicate that the metallacycle forming transition state is not rate (selectivity) determining, we will not discuss this point any further.

\begin{tabular}{|c|c|c|c|c|}
\hline Functional & $\begin{array}{l}\text { Transition } \\
\text { State }\end{array}$ & $\begin{array}{c}\Delta E^{\neq} \text {cis-trans } \\
\text { gas-phase }\end{array}$ & $\begin{array}{c}\Delta G^{\neq}{ }_{\text {cis-trans }} \\
\text { gas-phase }\end{array}$ & $\begin{array}{c}\Delta G^{\neq} \text {cis-trans } \\
\mathrm{CH}_{2} \mathrm{Cl}_{2}\end{array}$ \\
\hline \multirow{4}{*}{ BP86 } & TS1-trans & 0.0 & 0.0 & 0.0 \\
\hline & TS1-cis & 0.2 & 1.2 & 1.4 \\
\hline & TS2-trans & 4.5 & 4.1 & 4.1 \\
\hline & TS2-cis & 4.1 & 3.8 & 3.8 \\
\hline \multirow{4}{*}{ B3LYP } & TS1-trans & 0.0 & 0.0 & 0.0 \\
\hline & TS1-cis & 0.5 & 0.1 & 0.3 \\
\hline & TS2-trans & 4.2 & 3.3 & 3.2 \\
\hline & TS2-cis & 3.7 & 2.1 & 2.0 \\
\hline \multirow{4}{*}{ M06L } & TS1-trans & 0.0 & 0.0 & 0.0 \\
\hline & TS1-cis & 0.1 & 2.3 & 2.2 \\
\hline & TS2-trans & 6.0 & 6.5 & 5.6 \\
\hline & TS2-cis & 4.6 & 5.7 & 5.4 \\
\hline \multirow{4}{*}{ M06 } & TS1-trans & 0.0 & 0.0 & 0.0 \\
\hline & TS1-cis & 0.6 & 0.6 & 0.5 \\
\hline & TS2-trans & 4.9 & 4.6 & 4.2 \\
\hline & TS2-cis & 4.3 & 4.6 & 4.1 \\
\hline
\end{tabular}


Focusing on the metallacycle breaking transition state, the values in Table 1 indicate that the difference between the TS2cis and TS2-trans transition states is somewhat dependent on the computational approach used. Indeed, the BP86, B3LYP and M06L results suggest that the TS2-cis transition state is somewhat preferred over the TS2-trans transition state, thus suggesting a small preference for the formation of cis-olefins. The M06 functional, instead, indicates that these two transition states are practically of the same energy. Further, the values given in Table 1 indicate that in terms of gas-phase potential energy the TS2-cis is reasonably favored over TS2-trans also with the M06 functional. It is the inclusion of the vibrational/ entropic part that makes the M06 cis- and trans transition states of similar energy, (compare the $\Delta E^{\neq}$cis-trans and $\Delta G^{\neq}$cis-trans values in the gas-phase in Table 1). Inclusion of solvent effects does not change the gas-phase trends (compare the $\Delta G^{\neq}$cis-trans in gas-phase and the $\Delta G^{\neq}$cis-trans in $\mathrm{CH}_{2} \mathrm{Cl}_{2}$ values in Table 1). In conclusion, if any preference exists at the level of the metallacycle breaking step, the consensus emerging from the comparison of various functionals is that the cis transition state is favored. The fact that the cis transition state is of lower or similar energy to the trans transition state, despite of the higher stability of the forming trans $\mathrm{C}=\mathrm{C}$ skeleton, indicates that the SIMes ligand is more suitable to host a cis forming $\mathrm{C}=\mathrm{C}$ bond rather than a trans $\mathrm{C}=\mathrm{C}$ bond.

Based on these calculations, the conclusion emerging from the energy profiles of Figure 1 and the values given in Table 1 is that, in the framework of a dissociative mechanism, the key step determining the experimentally observed preferential formation of trans-olefins is product release with formation of the methylidene $\mathrm{Ru} 14 \mathrm{e}$ intermediate $\mathbf{1 4} \mathbf{e} \mathbf{2}$ and a free cis- or trans2-butene molecule from Co2-cis and Co2-trans (in this regard it must be noted that an associative mechanism has been proposed to be operative for ethylene degenerate metathesis at low temperature $[31,32]$, and for the activation step in Hoveyda/ Grela type catalysts [33]). Product release is endoergonic due to the coordination energy of 2-butene that amounts to roughly 6 $\mathrm{kcal} \cdot \mathrm{mol}^{-1}$ both for the cis- and trans-isomers, and is clearly higher in energy than both TS2 transition states that would revert the just formed 2-butenes into the most stable metallacycle. For this reason, the energy profile of Figure 1 suggests that the most likely event from Co2-cis and Co2-trans is not product release, but rather their transformation into MCy2-cis and MCy2-trans. The escape from Co2-cis and Co2-trans is controlled by the free energy difference between $14 \mathrm{e} 2$ and transition states TS2-cis and TS2-trans, which amounts to 3.6 and $2.5 \mathrm{kcal} \cdot \mathrm{mol}^{-1}$ for the cis and trans pathways, respectively. These numbers indicate that release of trans-2-butene is favored by the higher stability of the trans-olefin relative to the cisisomer.
Of course, considering the high reactivity of both trans- and cisbutene towards metathesis, it is clear that secondary metathesis of the produced butenes, whose energetic can be still derived from Figure 1, will result in a statistical distribution of the products according to their thermodynamic stability $[15,18]$. Thus, a high trans/cis-butene ratio would be reached, even if a lower trans/cis ratio was initially produced. This conclusion is in qualitative agreement with $\mathrm{CM}$ experiments using terminal olefins, which resulted in a trans/cis ratio of around 2-4 at low conversions, that increased to $9-10$ at higher conversions [18]. Finally, it is clear that the steric and electronic properties of more complex olefins can have a strong impact on the energy profile of Figure 1, which however, remains the base energy profile to be modified. We are currently working in this direction.

\section{Conclusion}

In this study we have investigated computationally the origin of the cis-trans selectivity in the CM of the prototype monosubstituted olefin, i.e., propene. Our calculations suggest that the origin of the preferential formation of trans-olefins is not the energy difference at the transition states corresponding to either metallacycle formation of breaking. Actually, focusing on the transition state higher in energy (the one corresponding to metallacycle breaking), we found that the transition state leading to the formation of cis-butene is of similar energy, or even favored, relative to that leading to the formation of transbutene. Thus, CM of propene (and by consequence of simple linear 1-olefins) should kinetically lead first to the formation of cis-olefins, followed by gradual conversion to the more stable trans-isomer. Our calculations suggest that the key step to rationalize the preferential formation of trans-olefins, even at low conversion, is in the product release step, since trans-olefins have a higher tendency to be released from the catalyst at the end of the CM reaction. Conversely, the initially formed cisolefins have a minor tendency to be released from the catalyst, and thus they have a higher chance to return to the reaction pool until the trans-olefin is formed.

\section{Experimental Computational Details}

The DFT calculations of the full energy profile of Figure 1 were performed at the HMGGA level with the Gaussian09 package [34], using the M06 functional of Truhlar [23]. Free energies in $\mathrm{CH}_{2} \mathrm{Cl}_{2}$ were deduced from the gas-phase free energies plus the solvation energy term estimated in single point calculations on the gas-phase optimized structures, based on the polarizable continuum solvation model PCM using $\mathrm{CH}_{2} \mathrm{Cl}_{2}$ as the solvent [35]. In case of olefin coordination, we assumed a $-T \Delta S$ contribution of $10 \mathrm{kcal} \cdot \mathrm{mol}^{-1}$, since the gas-phase rotational/translational entropy of coordination from classical statistical thermo- 
dynamics is generally considered to overestimate the coordination entropy in solution. The $-T \Delta S$ contribution of 10 $\mathrm{kcal} \cdot \mathrm{mol}^{-1}$ is the experimental coordination entropy of $\mathrm{C}_{2} \mathrm{H}_{4}$ to a Pd-complex [36]. The test calculations in Table 1 were performed with the GGA BP86 functional of Becke and Perdew [24-26], with the HGGA B3LYP functional of Becke, Lee, Parr, and Yang [27-29], and with the MGGA M06L functional of Truhlar [30]. In all cases the electronic configuration of the molecular systems was described with the standard splitvalence basis set with a polarization function of Ahlrichs and co-workers for $\mathrm{H}, \mathrm{C}, \mathrm{N}, \mathrm{O}$ and $\mathrm{Cl}$ (SVP keyword in Gaussian03) [37]. For Ru we used the small-core, quasi-relativistic Stuttgart/Dresden effective core potential, with an associated $(8 \mathrm{~s} 7 \mathrm{p} 6 \mathrm{~d}) /[6 \mathrm{~s} 5 \mathrm{p} 3 \mathrm{~d}]$ valence basis set (SDD keywords in Gaussian03) [38]. Characterization of the located stationary points as minima or transition state was performed by frequency calculations.

\section{Acknowledgements}

We thank M. Barbasiewicz, Warsaw University, for useful discussions. The research leading to these results received funding from the European Community's Seventh Framework Programme (FP7/2007-2013) under grant agreement $n^{\circ}$ CP-FP 211468-2 EUMET. LC thanks the HPC team of Enea (http:// www.enea.it) for use of the ENEA-GRID and the HPC facilities CRESCO (http://www.cresco.enea.it) in Portici, Italy.

\section{References}

1. Grubbs, R. H. Handbook of Olefin Metathesis; Wiley-VCH: Weinheim, Germany, 2003.

2. Connon, S. J.; Blechert, S. Angew. Chem., Int. Ed. 2003, 42 , 1900-1923. doi:10.1002/anie.200200556

3. Samojłowicz, C.; Bieniek, M.; Grela, K. Chem. Rev. 2009, 109, 3708-3742. doi:10.1021/cr800524f

4. Vougioukalakis, G. C.; Grubbs, R. H. Chem. Rev. 2010, 110, 1746-1787. doi:10.1021/cr9002424

5. Malacea, R.; Fischmeister, C.; Bruneau, C.; Dubois, J.-L.; Couturier, J.-L.; Dixneuf, P. H. Green Chem. 2009, 11, 152-155. doi:10.1039/b816917a

6. Rybak, A.; Meier, M. A. R. Green Chem. 2007, 9, 1356-1361. doi:10.1039/b712293d

7. Demchuk, O. M.; Pietrusiewicz, K. M.; Michrowska, A.; Grela, K. Org. Lett. 2003, 5, 3217-3220. doi:10.1021/ol035011m

8. Cantrill, S. J.; Grubbs, R. H.; Lanari, D.; Leung, K. C. F.; Nelson, A.; Poulin-Kerstien, K. G.; Smidt, S. P.; Stoddart, J. F.; Tirrell, D. A. Org. Lett. 2005, 7, 4213-4216. doi:10.1021/ol051599g

9. Chatterjee, A. K.; Sanders, D. P.; Grubbs, R. H. Org. Lett. 2002, 4, 1939-1942. doi:10.1021/ol0259793

10. Boeda, F.; Bantreil, X.; Clavier, H.; Nolan, S. P. Adv. Synth. Catal. 2008, 350, 2959-2966. doi:10.1002/adsc.200800495

11. Berlin, J. M.; Goldberg, S. D.; Grubbs, R. H. Angew. Chem., Int. Ed. 2006, 45, 7591-7595. doi:10.1002/anie.200602469

12. Stewart, I. C.; Douglas, C. J.; Grubbs, R. H. Org. Lett. 2008, 10, 441-444. doi:10.1021/ol702624n
13. Funk, T. W.; Efskind, J.; Grubbs, R. H. Org. Lett. 2005, 7, 187-190. doi:10.1021/ol047929z

14. Chatterjee, A. K.; Grubbs, R. H. Org. Lett. 1999, 1, 1751-1753. doi:10.1021/ol991023p

15. Chatterjee, A. K.; Choi, T.-L.; Sanders, D. P.; Grubbs, R. H. J. Am. Chem. Soc. 2003, 125, 11360-11370. doi:10.1021/ja0214882

16. Choi, T.-L.; Chatterjee, A. K.; Grubbs, R. H. Angew. Chem., Int. Ed. 2001, 40, 1277-1279. doi:10.1002/1521-3773(20010401)40:7<1277::AID-ANIE1277>3.0.CO; 2-E

17. Smith, A. B., III; Adams, C. M.; Kozmin, S. A. J. Am. Chem. Soc. 2001, 123, 990-991. doi:10.1021/ja003745d

18. Anderson, D. R.; Ung, T.; Mkrtumyan, G.; Bertrand, G.; Grubbs, R. H.; Schrodi, Y. Organometallics 2008, 27, 563-566. doi:10.1021/om7008028

19. Aagaard, O. M.; Meier, R. J.; Buda, F. J. Am. Chem. Soc. 1998, 120, 7174-7182. doi:10.1021/ja974131k

20. van der Eide, E. F.; Piers, W. E. Nat. Chem. 2010, 2, 571-576. doi:10.1038/nchem.653

21. Rowley, C. N.; van der Eide, E. F.; Piers, W. E.; Woo, T. K. Organometallics 2008, 27, 6043-6045. doi:10.1021/om8008519

22. Lide, D. R. Handbook of Chemistry and Physics, 84th ed.; CRC Press Inc.: London, 2004.

23. Zhao, Y.; Truhlar, D. G. Theor. Chem. Acc. 2008, 120, 215-241. doi:10.1007/s00214-007-0310-x

24. Becke, A. D. Phys. Rev. A 1988, 38, 3098-3100. doi:10.1103/PhysRevA.38.3098

25. Perdew, J. P. Phys. Rev. B 1986, 33, 8822-8824. doi:10.1103/PhysRevB.33.8822

26. Perdew, J. P. Phys. Rev. B 1986, 34, 7406. doi:10.1103/PhysRevB.34.7406

27. Becke, A. D. J. Chem. Phys. 1993, 98, 5648-5652. doi:10.1063/1.464913

28. Lee, C.; Yang, W.; Parr, R. G. Phys. Rev. B 1988, 37, 785-789. doi:10.1103/PhysRevB.37.785

29. Stephens, P. J.; Devlin, F. J.; Chabalowski, C. F.; Frisch, M. J. J. Phys. Chem. 1994, 98, 11623-11627. doi:10.1021/j100096a001

30. Zhao, Y.; Truhlar, D. G. J. Chem. Phys. 2006, 125, 194101. doi:10.1063/1.2370993

31. Romero, P. E.; Piers, W. E. J. Am. Chem. Soc. 2007, 129, 1698-1704. doi:10.1021/ja0675245

32. Webster, C. E. J. Am. Chem. Soc. 2007, 129, 7490-7491. doi:10.1021/ja071588d

33. Vorfalt, T.; Wannowius, K.-J.; Plenio, H. Angew. Chem., Int. Ed. 2010, 49, 5533-5536. doi:10.1002/anie.201000581

34. Gaussian 03, B. 1; Gaussian, Inc.: Pittsburg PA, 2003.

35. Tomasi, J.; Persico, M. Chem. Rev. 1994, 94, 2027-2094. doi:10.1021/cr00031a013

36. Rix, F. C.; Brookhart, M. J. Am. Chem. Soc. 1995, 117, 1137-1138. doi:10.1021/ja00108a034

37. Schäfer, A.; Horn, H.; Ahlrichs, R. J. Chem. Phys. 1992, 97 , 2571-2577. doi:10.1063/1.463096

38. Küchle, W.; Dolg, M.; Stoll, H.; Preuss, H. J. Chem. Phys. 1994, 100, 7535-7542. doi:10.1063/1.466847 


\section{License and Terms}

This is an Open Access article under the terms of the Creative Commons Attribution License

(http://creativecommons.org/licenses/by/2.0), which permits unrestricted use, distribution, and reproduction in any medium, provided the original work is properly cited.

The license is subject to the Beilstein Journal of Organic Chemistry terms and conditions:

(http://www.beilstein-journals.org/bjoc)

The definitive version of this article is the electronic one which can be found at:

doi:10.3762/bjoc.7.7 